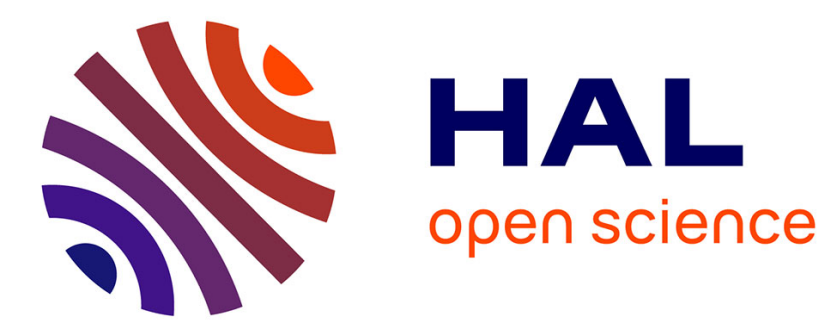

\title{
Chemical properties of the possible Titan's alkanofer
}

Daniel Cordier, David Bonhommeau

\section{To cite this version:}

Daniel Cordier, David Bonhommeau. Chemical properties of the possible Titan's alkanofer. Europlanet Science Congress 2020, Sep 2020, Reims Virtual Congress, France. hal-03044401

\section{HAL Id: hal-03044401 \\ https://hal.science/hal-03044401}

Submitted on 7 Dec 2020

HAL is a multi-disciplinary open access archive for the deposit and dissemination of scientific research documents, whether they are published or not. The documents may come from teaching and research institutions in France or abroad, or from public or private research centers.
L'archive ouverte pluridisciplinaire HAL, est destinée au dépôt et à la diffusion de documents scientifiques de niveau recherche, publiés ou non, émanant des établissements d'enseignement et de recherche français ou étrangers, des laboratoires publics ou privés. 


\section{Chemical properties of the possible Titan's alkanofer}

Daniel Cordier and David A. Bonhommeau

CNRS, GSMA, REIMS, France (daniel.cordier@univ-reims.fr)

\section{Introduction}

Titan, the biggest satellite of Saturn, is the only satellite of the solar system possessing a dense atmosphere. This atmosphere, whose composition

is dominated by nitrogen and methane, habors a complexe chemistry initiated by the photolysis of these species. Among a plethora of molecules, ethane dominates, in quantity, the products of the atmospheric chemistry. Since the Voyager flyby, the existence of liquid bodies at the surface of Titan has been suspected. Thanks to its radar, which had the capability of imaging the surface through the atmosphere

opaque to visible light, the Cassini orbiter instruments have revealed a collection of dark features dotting the polar regions

(Stofan et al. 2007, Turtle et al., 2009). These geomorphological characteristics are interpreted as lakes or seas (depending on their size)

of liquid hydrocarbons. These structures were found at both poles and involve diameters up to more than hundreds of kilometers.

Recently, Titan's surface altimetry investigations have shown that several Maria share the same equipotential for their free surface

(Corlies et al., 2017, Hayes et al., 2017). These new measurements suggest the existence of some local subsurface connectivity between

liquid bodies. The concept of an alkanofer, analog of terrestrial aquifer, has been already proposed in the literature

(Mousis et al. 2014, Mousis et al. 2016). Such an alkanofer consists of a mixture of liquid hydrocarbons trapped in a porous icy crust.

On the Earth, beside already mentioned aquifers, alkanofers also exist and are called hydrocarbon reservoirs, they contain

petroleum and gases. For many decades, field measurements have revealed a wide range of compositional variation in these reservoirs. These variations

are most of the time vertical (Metcalfe et al. 1988), while horizontal cases are also observed. In general, the lightest hydrocarbons are found at

the top of the reservoir, while the heaviest molecules are buried at the bottom of the system.

In the context of Titan, one may wonder whether such a chemical stratification could appear within an alkanofer mainly composed by

a liquid mixture of methane, ethane and dissolved nitrogen. This question is important, specifically for the "problem of missing ethane" (Gilliam \& Lerman, 2016); in addition, investigations 
concerning this system are also related to the Titan's

hydrological cycle (Horvath et al., 2016). Finally, and more generally, the nature, the amplitude and the temporality of exchanges between Titan's

interior and its atmosphere is a very important " cold case" for which any advanced is welcome (Nixon et al., 2018).

\section{A Model of Chemical Stratification of the Possible Alkanofer}

Since the convection is often inhibited in hydrocarbon reservoirs, the transport process at work is based on diffusion processes.

In the general case, the evolution of the mole fraction $x_{\mathrm{i}}$ of a species $i$ with $z$, the depth in the alkanofer, is governed by two

equations (Bird et al., 1960, Ghorayeb \& Firoozabadi 2000)

$$
\begin{aligned}
& \left.\frac{\partial \ln f_{i}}{\partial \ln x_{i}}\right|_{P, T} \vec{\nabla} x_{i}+\frac{x_{i}}{R T}\left(\bar{V}_{i}-\frac{M_{i}}{\rho_{\text {liq }}}\right) \vec{\nabla} P \\
& +\frac{k_{T i, j}}{T} \vec{\nabla} T=0 \\
& \frac{\partial P}{\partial z}=-\rho_{\mathrm{eff}} g_{\mathrm{Tit}}
\end{aligned}
$$

The first term of Eq. 1 represents the usual molecular fickean diffusion, the second term the barodiffusion due to the gradient of pressure, and the third one takes account for the thermodiffusion caused by the temperature gradient. Usual notation has been used: $f_{\mathrm{i}}$ is the fugacity, $R$ the gas constant, $V_{\mathrm{i}}$ the partial molar volume and $M_{\mathrm{i}}$ the molecular weight of species $i$. The density of the liquid is $\rho_{\text {liq, }}$ while $k_{T, i j}$ denotes the thermal diffusion ratio. Obviously, Eq. 2 is the hydrostatic equilibrium of Titan's crust, where the density $\rho_{\text {eff }}$ takes into account the weight of the wate ice Ih. 


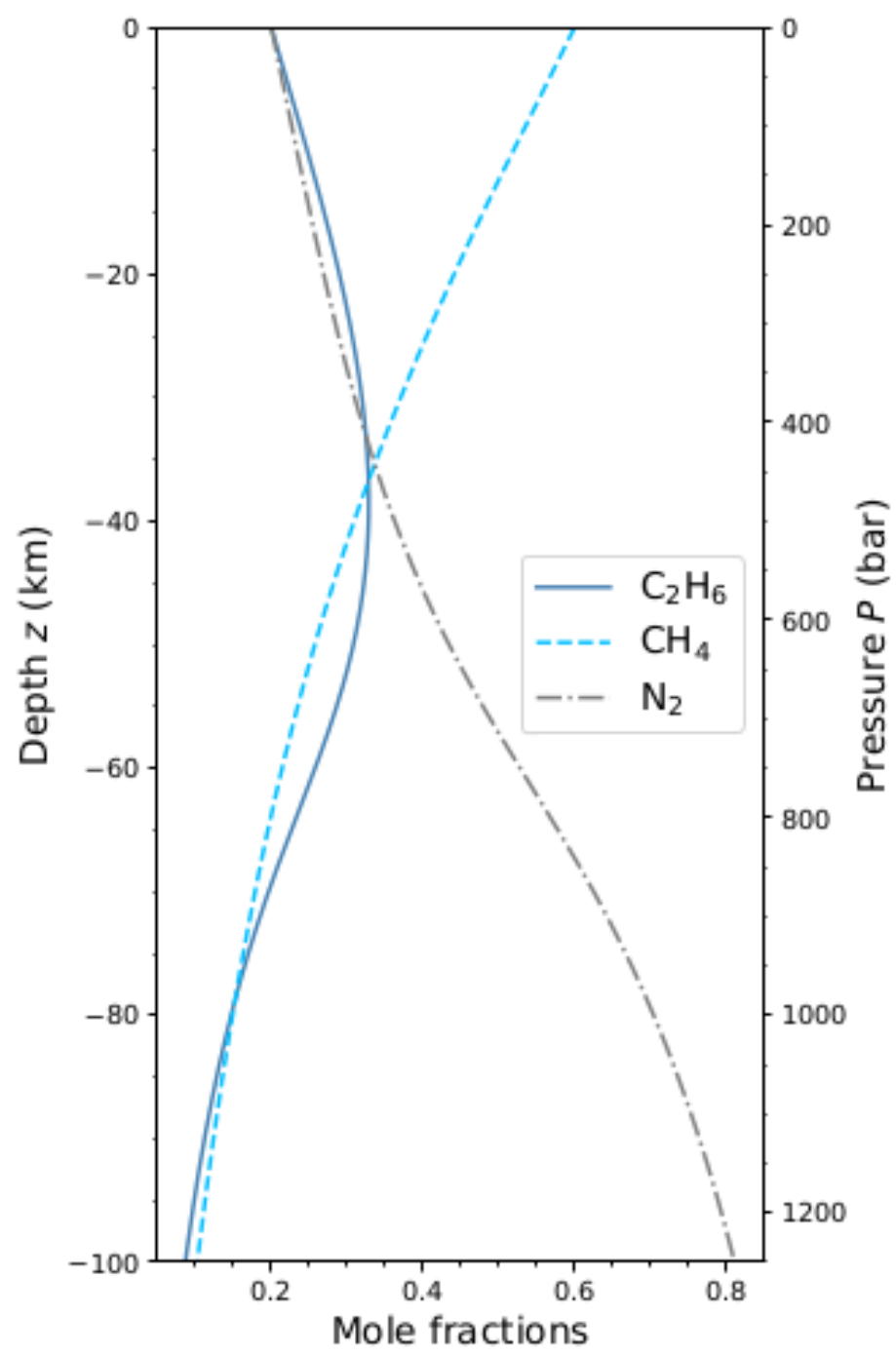

Since the evaluation of $k_{T, i j}$ is not straightforward, we have chosen, in a first approach, to neglect the temperature effect.

This preliminary model is then a Titan's isothermal crust made of a $\mathrm{N}_{2}+\mathrm{CH}_{4}+\mathrm{C}_{2} \mathrm{H}_{6}$ liquid mixture trapped in a Ih-ice matrix. The properties

of the liquid mixture is described by the PC-SAFT equation of state. The results for an isothermal crust at $T=90 \mathrm{~K}$ are plotted in

Fig. 1. Not surprisingly, heaviest compounds have their mole fractions increasing down to approximately $-35 \mathrm{~km}$. Below this depth,

the separation beween nitrogen and hydrocarbons was not a priori expected. In this presentation we will discuss the existence of liquids

at high depth and the possible explanation for the mentioned separation.

In a second step, we will present our non-isothermal model which is based on: (1) a reconstruction of the geophysical temperature gradient,

(2) a derivation of the thermal diffusion coefficient from the equation of state PC-SAFT. The model of interior structure relies on a non-convecting

crust (Nimmo \& Bills, 2010) for which we included hydrostatic equilibrium, energy conservation and energy flux equations (Sohl et al., 2014).

The temperature law produced by this model is used as an input of a "chemical model" based on Eq. 1 and 2, where

$k_{\mathrm{T}, \mathrm{ij}}$ 's are derived from PC-SAFT, like we did for other quantities: $f_{\mathrm{i},}, V_{\mathrm{i}}$ and $\rho_{\text {liq }}$. 
Our presentation is complemented by a detailed discussion of involved timescales related to Titan's alkanofers formation. We also consider the role of such alkanofers in the release of geologic argon into the atmosphere.

\section{References}

Bird, Stewart and Lightfoot, 1960, Transport Phenomena, John Wiley and Sons, New York.

Corlies, Hayes, Birch, Lorenz, R. Stiles, Kirk, Poggiali, Zebker, Iess, 2017, GRL, 44, 11.

Ghorayeb, Firoozabadi, 2000, AIChe], 46, 883.

Gilliam, \& Lerman, A. 2016, Icarus, 275, 252.

Hayes, Birch, Dietrich, Howard, Kirk, Poggiali, Mastrogiuseppe, Michaelides, Corlies, Moore, Malaska, Mitchell, Lorenz, Wood, 2017, GRL, 44, 11

Horvath, Andrews-Hanna, Newman, Mitchell, Stiles, 2016, Icarus, 277, 103

Metcalfe, Vogel, Morris, R. W. 1988, SPE.

Mousis, Choukroun, Lunine, Sotin, 2014, Icarus, 239, 39.

Mousis, Lunine, Hayes, Hofgartner, J. D., Icarus, 270, 37. Nimmo, F., \& Bills, B. G. 2010, Icarus, 208, 896.

Nixon, Lorenz, Achterberg, et al. 2018, PSS, 155, 50.

Sohl, Solomonidou, Wagner, et al. 2014, JGR, 119, 1013.

Stofan, Elachi, Lunine, et al. 2007, Nature, 445, 61

Turtle, Perry, McEwen, et al. 2009, GRL, 36, 2204 